\title{
Impact of antitumor regimens on the outcomes of cancer patients with COVID-19: a pooled analysis
}

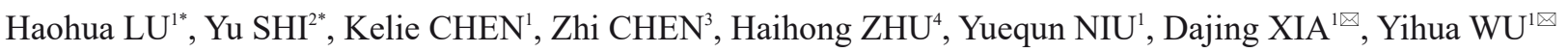 \\ ${ }^{I}$ Department of Toxicology of School of Public Health and Department of Gynecologic Oncology of Women's Hospital, School of Medicine, \\ Zhejiang University, Hangzhou 310058, China \\ ${ }^{2}$ The State Key Laboratory for Diagnosis and Treatment of Infectious Diseases, the First Affiliated Hospital, School of Medicine, Zhejiang \\ University, Hangzhou 310003, China \\ ${ }^{3}$ Collaborative Innovation Center for Diagnosis and Treatment of Infectious Diseases, Hangzhou 310003, China \\ ${ }^{4}$ National Clinical Research Center for Infectious Diseases, Hangzhou 310003, China
}

Since the outbreak of coronavirus disease 2019 (COVID-19), which is caused by the severe acute respiratory syndrome coronavirus 2 (SARS-CoV-2) discovered in December 2019, the disease has emerged as a global pandemic (Shi et al., 2020; World Health Organization, 2020). Several studies have shown a higher incidence of COVID-19, as well as related poor outcomes in patients with malignancies as compared with those without them (Liang et al., 2020; Tian et al., 2020). The impact of cancer on COVID-19 may be attributed to the use of antitumor treatments that may disturb the host response to SARS-CoV-2 infection (Wang et al., 2020), while the current studies on this topic have drawn controversial conclusions. Some implied that anticancer treatments might elevate the risk of death (García-Suárez et al., 2020; Liu et al., 2020). On the contrary, others pointed out that this association is not significant (Brar et al., 2020; Lee et al., 2020a). Although previous systematic reviews have investigated this important issue (Wang and Huang, 2020), the heterogeneity of findings is obvious and the general conclusion has remained unclear. Considering this ambiguity, it is difficult for clinicians to make therapeutic decisions when facing patients with both cancer and

\footnotetext{
\Yhua WU, georgewu@zju.edu.cn

Dajing XIA, dxia@zju.edu.cn

The two authors contributed equally to this work

(D) Yihua WU, https://orcid.org/0000-0001-7952-4090

Dajing XIA, https://orcid.org/0000-0003-1645-9046

Received Feb. 10, 2021; Revision accepted July 19, 2021; Crosschecked Sept. 15, 2021
}

(C) Zhejiang University Press 2021
COVID-19; therefore, a high-quality and accurate evaluation of the impact of anticancer treatments on COVID-19 patients is necessary. Accordingly, we conducted a pooled analysis with the original data of each patient for the first time to provide a comprehensive perspective into the association between anticancer regimens and the outcomes of cancer patients with COVID-19.

The study was carried out according to a predefined protocol submitted to the PROSPERO registry (CRD42020209305). After performing a search on PubMed, Embase, and Cochrane library for the period of January 1, 2019 to October 17, 2020, 5306 citations were identified, of which 1374 duplicate records were excluded. The review of titles and abstracts led to the exclusion of 3762 irrelevant citations, leaving 170 for further assessment. After reviewing the full texts of these citations, 11 studies were included for the final pooled analysis. The detailed inclusion criteria were listed in Appendix S1. The selection process is shown in Fig. 1, and the search strategy is detailed in Appendix S2.

During the assessment of the full texts, the studies that possibly reported on the same patients were carefully checked by the reviewers. Potential duplicate patients who were identified according to the information provided by the articles were removed. Finally, 11 studies with 394 participants were included in our research (Bertuzzi et al., 2020; Biernat et al., 2020; Bogani et al., 2020; Booth et al., 2020; Dai et al., 2020; Frey et al., 2020; Joharatnam-Hogan et al., 2020; Kalinsky et al., 2020; Wu et al., 2020; Zhang HY et al., 2020; Zhang L et al., 2020). In addition, 45 patients from three studies (Booth et al., 2020; Kalinsky et al., 


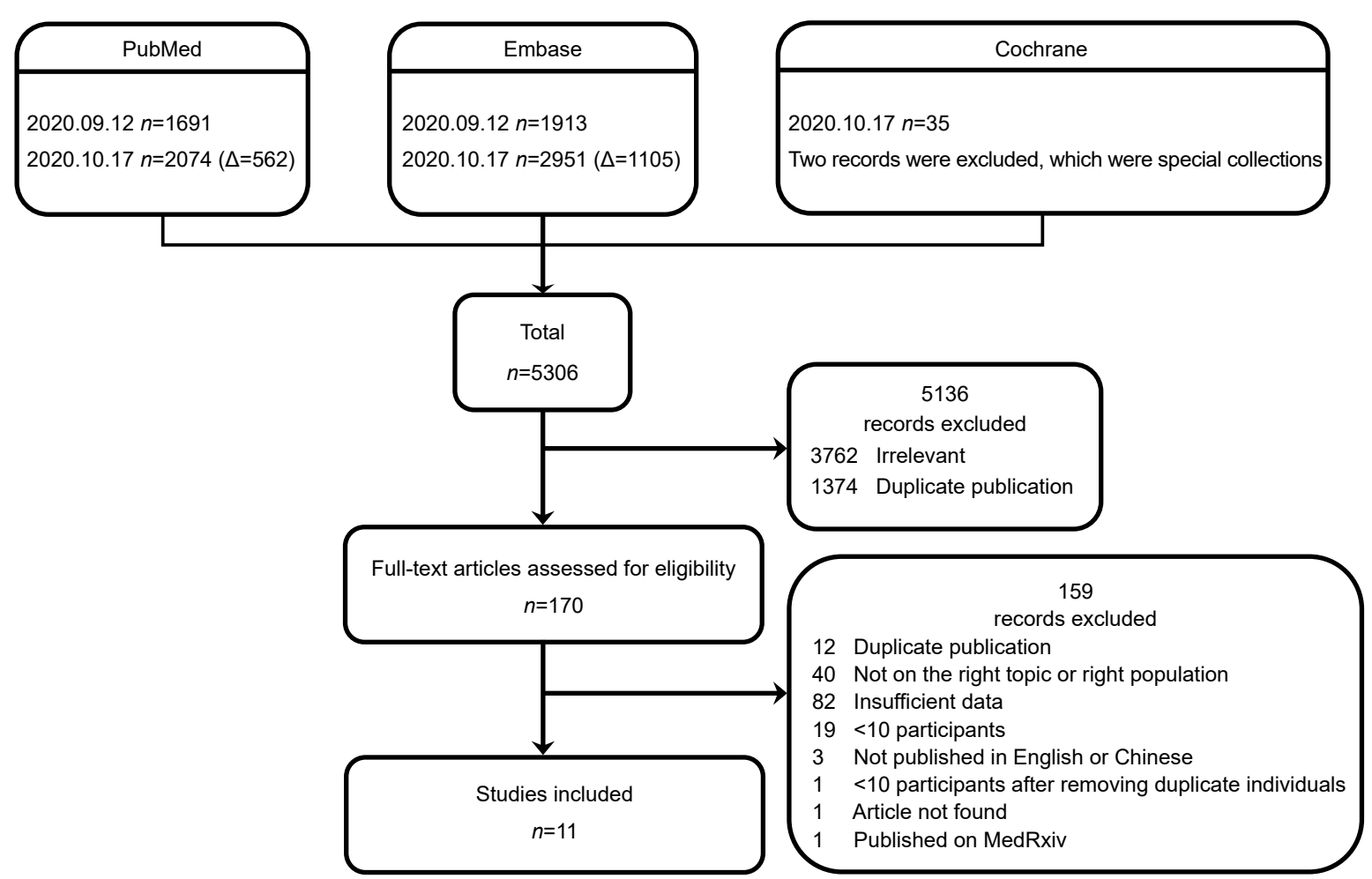

Fig. 1 Flow diagram of the study selection process. $\Delta$ : the remaining records after excluding the overlap between two rounds of literature search.

2020; Zhang HY et al., 2020) were excluded due to the uncertainty of the COVID-19 diagnostic results.

The following individual clinical data from each included study were extracted using a prospectively designed electronic data collection sheet: demographic information (gender, age, smoking habits, and comorbidities), the pattern of cancers, the details of antitumor regimens, the interval between anticancer treatments and COVID-19 onset, the primary outcome (all-cause mortality), and the secondary outcome (severe events, i.e., death, admission to an intensive care unit (ICU), and utilization of mechanical ventilation). The details of the involved studies are shown in Table 1.

Among the finally included 394 participants, the most commonly used antitumor regimen was chemotherapy (109 patients, 27.7\%), followed by targeted therapy (56 patients, $14.2 \%)$, hormonal therapy (39 patients, $9.9 \%$ ), radiotherapy (27 patients, $6.9 \%$ ), immunotherapy (26 patients, 6.6\%), and surgery (25 patients, $6.3 \%$ ) (Fig. 2a).

The subgroup analysis revealed that the use of chemotherapy was the most common in patients with solid tumors and patients from each of the three different regions (Figs. 2b and 2c).
The analysis results indicated that, regardless of tumor type or geographic region, chemotherapy was the most common antitumor treatment. Therefore, among the various anticancer regimens, chemotherapy was attributed important status.

We calculated the crude and adjusted odds ratios (ORs) and $95 \%$ confidence intervals $(95 \%$ CIs) to evaluate the impacts of antitumor regimens on the risks of primary (all-cause mortality) and secondary (severe events) outcomes. Based on the previous major studies (Lee et al., 2020a; Liu et al., 2021; Rüthrich et al., 2021), age, sex, smoking status, and comorbidities were regarded as potential confounders. According to our univariate analysis below, the covariables which were identified as significant risk factors were further included in multivariate analysis for adjustment. Moreover, we conducted a subgroup analysis by tumor type, gender, age, and the time period between treatments and the onset of COVID-19.

In total, 366 cancer patients with COVID-19 (ten studies) had a record of survival status, of which 91 patients $(24.9 \%)$ died from any cause. The univariate analysis revealed that receiving chemotherapy (OR, $1.88 ; 95 \% \mathrm{CI}, 1.13-3.13$ ) and hormonal therapy (OR, 
Table 1 Details of studies included in the analysis

\begin{tabular}{|c|c|c|c|c|c|c|}
\hline Study & Sample size & Country & Age (year) & Gender & Regimen & Tumor type \\
\hline Bertuzzi et al., 2020 & 26 & Italy & $43-89$ & Male/female & $\begin{array}{l}\text { Chemotherapy, immunotherapy, hormonal } \\
\text { therapy, and targeted therapy }\end{array}$ & Solid tumor \\
\hline Bogani et al., 2020 & 19 & Italy & $49-84$ & Female & $\begin{array}{l}\text { Surgery, chemotherapy, and targeted } \\
\text { therapy }\end{array}$ & $\begin{array}{l}\text { Gynecologic } \\
\text { cancer }^{*}\end{array}$ \\
\hline Booth et al., 2020 & 66 & UK & NA & Male/female & $\begin{array}{l}\text { Chemotherapy, targeted therapy, and } \\
\text { hormonal therapy }\end{array}$ & $\begin{array}{c}\text { Haematologic } \\
\text { malignancy }\end{array}$ \\
\hline Dai et al., 2020 & 105 & China & $26-87$ & Male/female & $\begin{array}{l}\text { Surgery, chemotherapy, immunotherapy, } \\
\text { targeted therapy, and radiotherapy }\end{array}$ & Not specified \\
\hline $\begin{array}{l}\text { Zhang HY et al., } \\
2020\end{array}$ & 107 & China & $36-98$ & Male/female & $\begin{array}{l}\text { Surgery, chemotherapy, immunotherapy, } \\
\text { targeted therapy, radiotherapy, and } \\
\text { hormonal therapy }\end{array}$ & Not specified \\
\hline Zhang L et al., 2020 & 28 & China & $24-80$ & Male/female & $\begin{array}{l}\text { Surgery, chemotherapy, immunotherapy, } \\
\text { targeted therapy, and radiotherapy }\end{array}$ & Solid tumor \\
\hline Biernat et al., 2020 & 10 & Poland & $30-69$ & NA & $\begin{array}{l}\text { Chemotherapy, targeted therapy, and } \\
\text { hormonal therapy }\end{array}$ & $\begin{array}{c}\text { Haematologic } \\
\text { malignancy }\end{array}$ \\
\hline $\begin{array}{l}\text { Kalinsky et al., } \\
2020\end{array}$ & 27 & USA & $32-80$ & Female & $\begin{array}{l}\text { Chemotherapy, immunotherapy, targeted } \\
\text { therapy, and hormonal therapy }\end{array}$ & Breast tumor \\
\hline Wu et al., 2020 & 11 & China & $29-73$ & Male/female & $\begin{array}{l}\text { Chemotherapy, immunotherapy, targeted } \\
\text { therapy, and radiotherapy }\end{array}$ & Not specified \\
\hline Frey et al., 2020 & 19 & USA & NA & Female & $\begin{array}{l}\text { Surgery, chemotherapy, immunotherapy, } \\
\text { targeted therapy, radiotherapy, and } \\
\text { hormonal therapy }\end{array}$ & $\begin{array}{l}\text { Gynecologic } \\
\text { cancer }^{*}\end{array}$ \\
\hline $\begin{array}{l}\text { Joharatnam-Hogan } \\
\text { et al., } 2020\end{array}$ & 26 & UK & $24-91$ & Male/female & $\begin{array}{l}\text { Surgery, chemotherapy, targeted therapy, } \\
\text { radiotherapy, and hormonal therapy }\end{array}$ & Not specified \\
\hline
\end{tabular}

NA, not available. * Gynecologic cancer in these studies includes primary malignancies in cancers of the ovary, vulva, cervix, uterus, and endometrium.

2.98; 95\% CI, 1.51-5.89) (Fig. 3) were associated with an increased risk of all-cause mortality. Besides, in the univariate analysis of 153 patients with relevant data (Bertuzzi et al., 2020; Dai et al., 2020; Kalinsky et al., 2020), age and a history of cardiovascular and cerebrovascular diseases were identified as significant variables $(P<0.05$; Table $\mathrm{S} 1)$ and were further included in multivariate analysis, which was performed for cases from six studies (Bertuzzi et al., 2020; Bogani et al., 2020; Dai et al., 2020; Kalinsky et al., 2020; Wu et al., 2020; Zhang HY et al., 2020) that provided complete relevant clinical information. In the multivariate analysis, we found no association between chemotherapy or hormonal therapy and increased risk of death (Fig. 4). It seemed that the clinical characteristics, such as advancing age, or cardiovascular and cerebrovascular diseases, played a more important role in disease outcomes than the antitumor regimens.

The OR for immunotherapy was significantly associated with an increased risk of all-cause mortality in solid tumor patients (OR, 2.66; 95\% CI, 1.07-6.64; 10 studies; Fig. 5). In patients with haematologic malignancies, chemotherapy increased the risk of death (OR, 4.11; 95\% CI, 1.59-10.60; 10 studies; Fig. 5). When stratified according to gender, hormonal therapy was significantly associated with death in male patients (OR, 8.09; 95\% CI, 2.09-31.30; 9 studies; Fig. 5). As for age, both chemotherapy (OR, 3.47; 95\% CI, 1.20-10.04; 8 studies) and immunotherapy (OR, 8.00; 95\% CI, 1.78-35.89; 8 studies) were associated with increased mortality in patients younger than 65 years, but not in those older than 65 years (Fig. 5). The impact of immunotherapy on mortality seemed to be more evident in younger patients. In elder patients, this impact could be diluted by other well-known factors, such as age and comorbidities. The time interval between recent anticancer treatments and the onset of COVID-19 was divided into "within 3 months" and "within $50 \mathrm{~d}$ " before the onset of COVID-19. For the former, the risk of all-cause mortality was increased in patients who had gone through chemotherapy (OR, 2.34; 95\% CI, 1.25-4.36; 6 studies), targeted therapy (OR, 2.37; 95\% CI, 1.15-4.88; 6 studies), and hormonal therapy (OR, 6.43; 95\% CI, 2.28-18.15; 6 studies) (Fig. 5). For the antitumor 

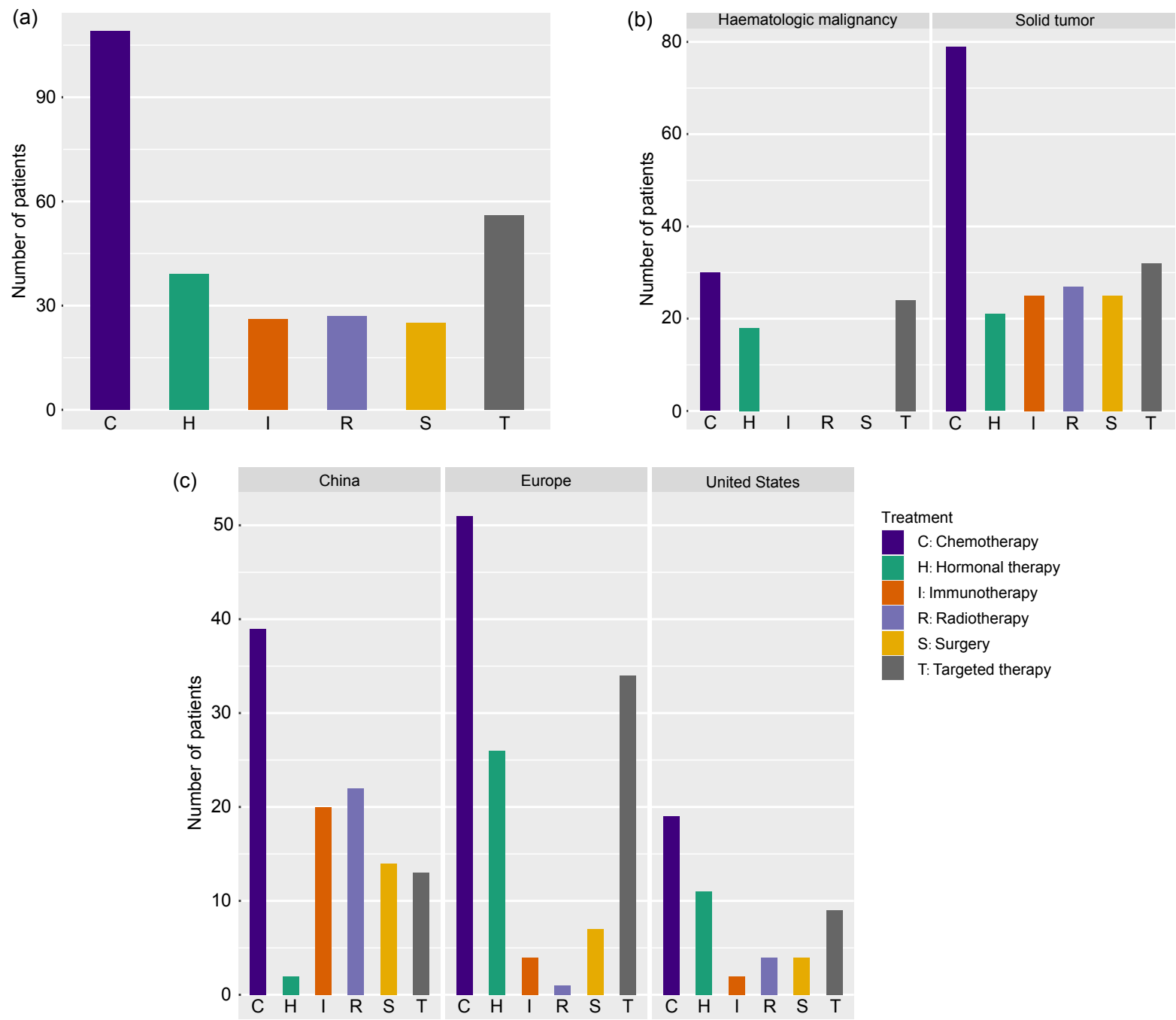

Fig. 2 Prevalence of different antitumor regimens in the overall population (a), and in patients stratified by tumor type (b) or geographic region (c).

\begin{tabular}{|c|c|c|c|c|}
\hline Treatment & $\begin{array}{l}\text { No. of events/total } \\
\text { treatment }\end{array}$ & $\begin{array}{c}\text { No. of events/total } \\
\text { control }\end{array}$ & & OR $(95 \% \mathrm{Cl})$ \\
\hline Surgery & $4 / 20$ & $87 / 346$ & $\rightarrow$ & 0.74 (0.24 to 2.29$)$ \\
\hline Chemotherapy & $33 / 97$ & $58 / 269$ & $\longmapsto$ & 1.88 (1.13 to 3.13$)$ \\
\hline Immunotherapy & $9 / 25$ & $82 / 341$ & & 1.78 (0.76 to 4.17$)$ \\
\hline Targeted therapy & $16 / 53$ & $75 / 313$ & $\longrightarrow$ & 1.37 (0.72 to 2.61$)$ \\
\hline Radiotherapy & $1 / 22$ & $90 / 344$ & & $0.13(0.02$ to 1.01$)$ \\
\hline Hormonal therapy & $18 / 39$ & $73 / 327$ & $\longrightarrow$ & 2.98 (1.51 to 5.89$)$ \\
\hline
\end{tabular}

Fig. 3 Univariate analysis of the associations between antitumor regimens and the risk of death. OR: odds ratio; CI: confidence interval.

regimens which were administered within $50 \mathrm{~d}$ before the onset of COVID-19, immunotherapy significantly increased the risk of all-cause mortality (OR, 3.57; 95\% CI, 1.41-9.01; 5 studies; Fig. 5), which was consistent with the overall result of multivariate analysis.
Overall, the subgroup analysis demonstrated that the adverse impacts of chemotherapy mainly occurred in patients with haematologic malignancies. However, for patients with solid tumors, immunotherapy could lead to life-threatening outcomes, especially when 
(a)

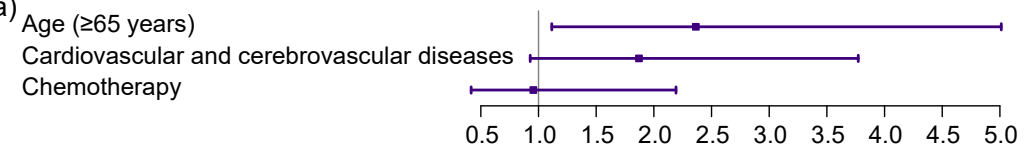

(b)

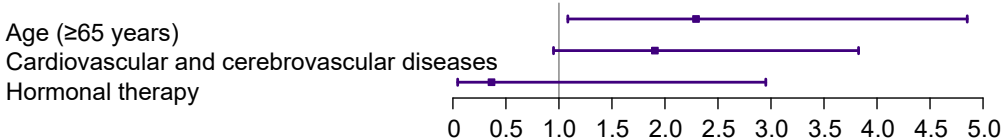

OR $(95 \% \mathrm{Cl}) \quad P$ value

2.36 (1.11 to 5.01 ) 0.025

1.87 (0.93 to 3.77$) \quad 0.08$

0.96 (0.42 to 2.19$) \quad 0.914$

OR $(95 \% \mathrm{Cl}) \quad P$ value

2.29 (1.08 to 4.85$) \quad 0.03$

1.91 (0.95 to 3.83$) \quad 0.07$

0.36 (0.04 to 2.95 ) 0.344

Fig. 4 Multivariate analysis of the associations between antitumor regimens (chemotherapy (a) and hormonal therapy (b)) and the risk of death. OR: odds ratio; CI: confidence interval.

administered within $50 \mathrm{~d}$. Both chemotherapy and immunotherapy were reported to affect SARS-CoV-2 antibody levels in patients and could influence the immune response to SARS-CoV-2 (Yazaki et al., 2021). In fact, some previous studies even indicated that chemotherapy increased the risk of poor outcomes (Grivas et al., 2021; Sharafeldin et al., 2021), especially in patients with haematologic malignancies (Lee et al., 2020b), which is in agreement with our results. For patients with haematologic malignancies, myelosuppressive chemotherapy could disrupt the immune system and contribute to a more severe form of COVID-19 (Lin et al., 2021). Furthermore, it was conferred that lymphocytopenia following myelosuppressive chemotherapy or lymphocyte-reducing chemotherapy in patients with haematologic malignancies correlated with a greater risk of severe or even a life-threatening form of COVID19 (Shi et al., 2020; Nakamura et al., 2021; Shumilov et al., 2021), which confirmed our finding for chemotherapy in patients with haematologic malignancies. Immunotherapy, including immune checkpoint blockage, chimeric antigen receptor (CAR) T-cell therapy, cancer vaccines, and tumor neoantigens, can reverse cancer immune evasion to eliminate cancer cells (Yang, 2015). Insufficient signaling through the programmed death-1 (PD-1) pathway following the administration of immune checkpoint inhibitors, which is commonly done in solid tumors, might lead to immunopathology in acute virus infection (Schönrich and Raftery, 2019). The pathological characteristics in a fatal case of COVID-19 revealed CD8 T-cells with high cytotoxicity (Xu et al., 2020), as observed in the toxicity of checkpoint inhibitors (Kennedy and Salama, 2020). Therefore, it can be speculated that the interplay between SARS-CoV-2 infection and immunotherapy might result in poor outcomes among special patients.

Considering the secondary outcome, 227 cancer patients with COVID-19 (four studies) had a record of severe events, in which 97 patients (42.7\%) developed severe events during follow-up.

In these studies, we carefully reviewed the definitions of "severe events." Thus, in view of the similarity of the definition of "severe events" in these four studies (Dai et al., 2020; Joharatnam-Hogan et al., 2020; Zhang HY et al., 2020; Zhang L et al., 2020), for subsequent analysis, we defined severe events as death, admission to an ICU, and utilization of mechanical ventilation.

The univariate analysis indicated that immunotherapy was significantly associated with the risk of severe events (OR, 5.75; 95\% CI, 1.19-27.73; Fig. S1). In addition, sex, age, and history of cardiovascular and cerebrovascular diseases with $P<0.05$ (Table S2) were included in multivariate analysis, which was conducted for cases in three studies (Dai et al., 2020; Zhang HY et al., 2020; Zhang L et al., 2020) providing sufficient relevant clinical information. When adjusted for the potential confounders (sex, age, and history of cardiovascular and cerebrovascular diseases), the effects of antitumor regimens on severe events became insignificant, while the effects of age and history of cardiovascular and cerebrovascular diseases remained significant (Fig. S2). Similar to the results of the primary outcome, the clinical characteristics seemed to be a more substantial risk factor in comparison with the antitumor regimens.

A subgroup analysis was also performed, which indicated that, for tumor type, immunotherapy increased the risk of severe events in solid tumor patients (OR, 5.04; 95\% CI, 1.02-24.86; 4 studies; Fig. 6). Considering the interval between antitumor treatments and the onset of COVID-19, immunotherapy given within $50 \mathrm{~d}$ significantly increased the risk of severe events (OR, 5.51; 95\% CI, 1.14-26.72; Fig. 6). Therefore, the use of immunotherapy significantly increased the risk of severe events in patients with solid tumors, especially when 


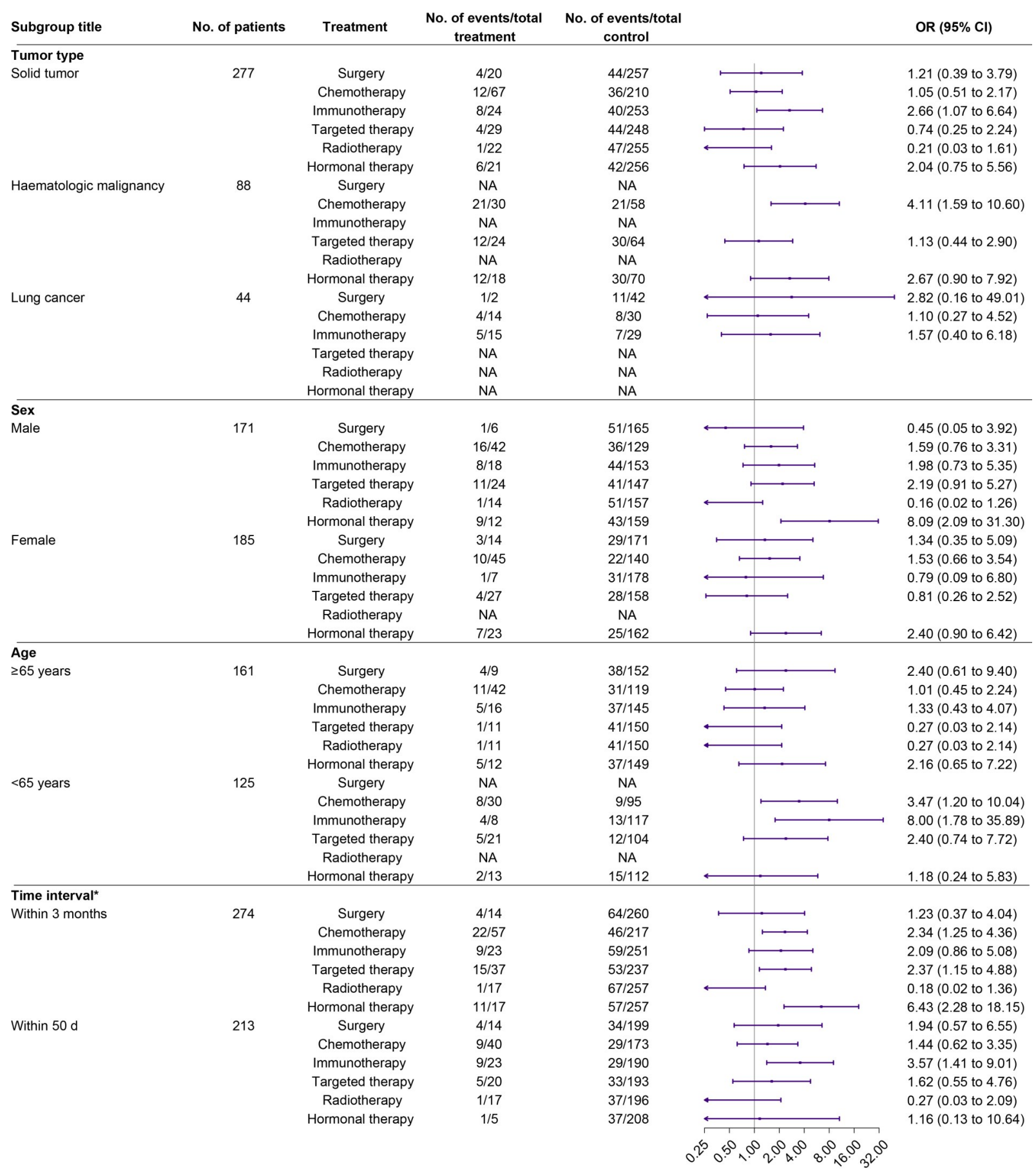

Fig. 5 Subgroup analysis of the associations between antitumor regimens and all-cause mortality. " Time interval between the treatment and the onset of COVID-19. NA: not available; OR: odds ratio; CI: confidence interval.

administered within $50 \mathrm{~d}$, which was in accordance with the result of the primary outcome.

In summary, our work provided a comprehensive review of anticancer regimens and their impacts on cancer patients with COVID-19. The findings showed that chemotherapy was the most common treatment in cancer patients with COVID-19. After adjustment, the effects of antitumor regimens on poor outcomes became insignificant, while the effects of advancing age and history of cardiovascular and cerebrovascular diseases remained significant, which indicated that crucial clinical characteristics such as age and comorbidity should 


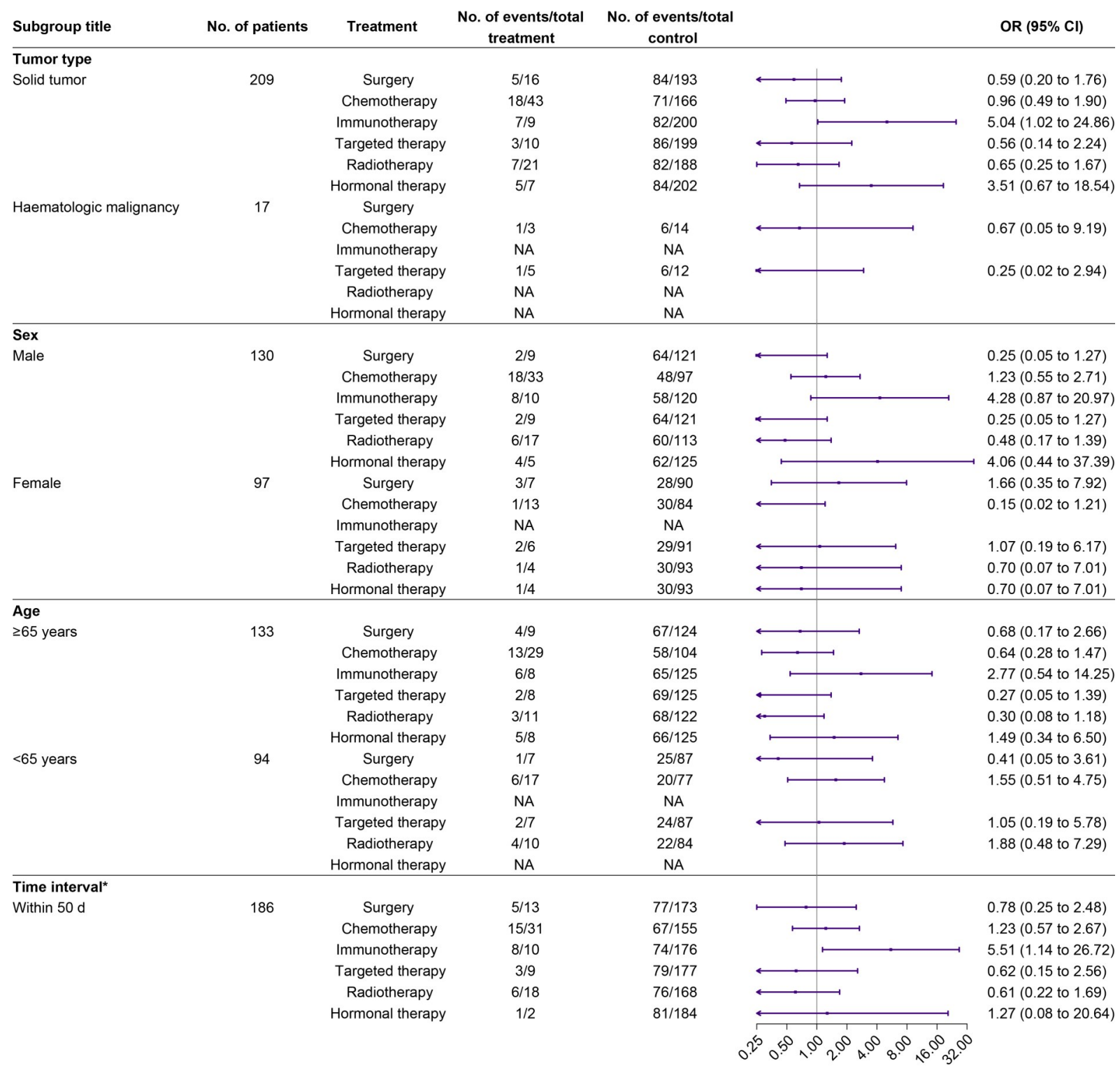

Fig. 6 Subgroup analysis of the associations between antitumor regimens and severe events. " Time interval between the treatment and the onset of COVID-19. NA: not available; OR: odds ratio; CI: confidence interval.

deserve more attention. According to the subgroup analysis, chemotherapy increased the risk of all-cause mortality in patients with haematologic malignancies. Furthermore, immunotherapy was associated with allcause mortality and severe events in patients with solid tumors, especially when given within $50 \mathrm{~d}$ before the onset of COVID-19. These findings can provide a basis for clinicians to tailor the regimens of anticancer treatments during the pandemic to minimize the impact of SARS-CoV-2 infection.

The present analysis has several limitations. Firstly, the number of studies with individual original data was insufficient, and the sample size was limited. Secondly, the quality and standard of data from different studies could not be fully controlled. Consequently, a multicenter study with a larger sample size and a unified standard of clinical data is strongly recommended. In addition, it appears that the combinational utilization of different treatments could reduce the side effects (Motz and Coukos, 2013). However, limited by the available clinical data, we did not investigate the effects of the combination of anticancer treatments on patients. Furthermore, as discussed above, the time interval between the recent anticancer treatments and the onset of COVID-19 
was not fully analyzed. A more accurate investigation in this respect should therefore be conducted.

\section{Acknowledgments}

This work was supported by the National Natural Science Foundation of China (Nos. 81773016 and 21976155), the Zhejiang Provincial Natural Science Foundation of China (No. LY18C060001), the Zhejiang Scientific and Technological Major Project under the 2020 Emergency (No. 2020C03124), the Zhejiang University Special Scientific Research Fund for COVID-19 Prevention and Control, and the Zhejiang Natural Project on Emergency Research about Community Prevention, Control, Early Warning and Prediction of the Novel Coronavirus Outbreak (No. LEZ20H260001).

\section{Author contributions}

Yihua WU and Dajing XIA contributed to the conception and design of the study. Haohua LU, Yu SHI, Yihua WU, Kelie CHEN, and Yuequn NIU contributed to data extraction, statistical analysis, and data interpretation. Haohua LU, Yu SHI, and Yihua WU contributed to writing the manuscript. Dajing XIA, Zhi CHEN, and Haihong ZHU contributed to editing the manuscript. All authors have read and approved the final manuscript and, therefore, have full access to all the data in the study and take responsibility for the integrity and security of the data.

\section{Compliance with ethics guidelines}

Haohua LU, Yu SHI, Kelie CHEN, Zhi CHEN, Haihong ZHU, Yuequn NIU, Dajing XIA, and Yihua WU declare that they have no conflict of interest.

This article does not contain any studies with human or animal subjects performed by any of the authors.

\section{References}

Bertuzzi AF, Marrari A, Gennaro N, et al., 2020. Low incidence of SARS-CoV-2 in patients with solid tumours on active treatment: an observational study at a tertiary cancer centre in Lombardy, Italy. Cancers, 12(9):2352. https://doi.org/10.3390/cancers12092352

Biernat MM, Zińczuk A, Biernat P, et al., 2020. Nosocomial outbreak of SARS-CoV-2 infection in a haematological unit - high mortality rate in infected patients with haematologic malignancies. J Clin Virol, 130:104574. https://doi.org/10.1016/j.jcv.2020.104574

Bogani G, Ditto A, Bosio S, et al., 2020. Cancer patients affected by COVID-19: experience from Milan, Lombardy. Gynecol Oncol, 158(2):262-265. https://doi.org/10.1016/j.ygyno.2020.06.161

Booth S, Willan J, Wong HN, et al., 2020. Regional outcomes of severe acute respiratory syndrome coronavirus 2 infection in hospitalised patients with haematological malignancy. Eur J Haematol, 105(4):476-483. https://doi.org/10.1111/ejh.13469
Brar G, Pinheiro LC, Shusterman M, et al., 2020. COVID-19 severity and outcomes in patients with cancer: a matched cohort study. J Clin Oncol, 38(33):3914-3924. https://doi.org/10.1200/jco.20.01580

Dai MY, Liu DB, Liu M, et al., 2020. Patients with cancer appear more vulnerable to SARS-CoV-2: a multicenter study during the COVID-19 outbreak. Cancer Discov, 10(6):783-791. https://doi.org/10.1158/2159-8290.CD-20-0422

Frey MK, Fowlkes RK, Badiner NM, et al., 2020. Gynecologic oncology care during the COVID-19 pandemic at three affiliated New York City hospitals. Gynecol Oncol, 159(2): 470-475. https://doi.org/10.1016/j.ygyno.2020.09.005

García-Suárez J, de la Cruz J, Cedillo Á, et al., 2020. Impact of hematologic malignancy and type of cancer therapy on COVID-19 severity and mortality: lessons from a large population-based registry study. J Hematol Oncol, 13:133. https://doi.org/10.1186/s13045-020-00970-7

Grivas P, Khaki AR, Wise-Draper TM, et al., 2021. Association of clinical factors and recent anticancer therapy with COVID-19 severity among patients with cancer: a report from the COVID-19 and cancer consortium. Ann Oncol, 32(6):787-800

https://doi.org/10.1016/j.annonc.2021.02.024

Joharatnam-Hogan N, Hochhauser D, Shiu KK, et al., 2020. Outcomes of the 2019 novel coronavirus in patients with or without a history of cancer: a multi-centre North London experience. Ther Adv Med Oncol, 12:1758835920956803. https://doi.org/10.1177/1758835920956803

Kalinsky K, Accordino MK, Hosi K, et al., 2020. Characteristics and outcomes of patients with breast cancer diagnosed with SARS-CoV-2 infection at an academic center in New York City. Breast Cancer Res Treat, 182:239-242. https://doi.org/10.1007/s10549-020-05667-6

Kennedy LB, Salama AKS, 2020. A review of cancer immunotherapy toxicity. CA: Cancer J Clin, 70(2):86-104. https://doi.org/10.3322/caac.21596

Lee LYW, Cazier JB, Angelis V, et al., 2020a. COVID-19 mortality in patients with cancer on chemotherapy or other anticancer treatments: a prospective cohort study. Lancet, 395(10241):1919-1926. https://doi.org/10.1016/s0140-6736(20)31173-9

Lee LYW, Cazier JB, Starkey T, et al., 2020b. COVID-19 prevalence and mortality in patients with cancer and the effect of primary tumour subtype and patient demographics: a prospective cohort study. Lancet Oncol, 21(10): 13091316. https://doi.org/10.1016/S1470-2045(20)30442-3

Liang W, Guan W, Chen R, et al., 2020. Cancer patients in SARS-CoV-2 infection: a nationwide analysis in China. Lancet Oncol, 21(3):335-337. https://doi.org/10.1016/s1470-2045(20)30096-6

Lin DD, Wu YH, Toom S, et al., 2021. Clinical determinants differentiating the severity of SARS-CoV-2 infection in cancer patients: hospital care or home recovery. Front Med (Lausanne), 8:604221. https://doi.org/10.3389/fmed.2021.604221

Liu C, Li L, Song KH, et al., 2020. A nomogram for predicting 
mortality in patients with COVID-19 and solid tumors: a multicenter retrospective cohort study. $J$ Immunother Cancer, 8(2):e01314 https://doi.org/10.1136/jitc-2020-001314

Liu Y, Lu H, Wang W, et al., 2021. Clinical risk factors for mortality in patients with cancer and COVID-19: a systematic review and meta-analysis of recent observational studies. Expert Rev Anticancer Ther, 21(1):107-119. https://doi.org/10.1080/14737140.2021.1837628

Motz GT, Coukos G, 2013. Deciphering and reversing tumor immune suppression. Immunity, 39(1):61-73. https://doi.org/10.1016/j.immuni.2013.07.005

Nakamura S, Kanemasa Y, Atsuta Y, et al., 2021. Characteristics and outcomes of coronavirus disease 2019 (COVID-19) patients with cancer: a single-center retrospective observational study in Tokyo, Japan. Int J Clin Oncol, 26(3): 485-493. https://doi.org/10.1007/s10147-020-01837-0

Rüthrich MM, Giessen-Jung C, Borgmann S, et al., 2021. COVID-19 in cancer patients: clinical characteristics and outcome - an analysis of the LEOSS registry. Ann Hematol, 100(2):383-393. https://doi.org/10.1007/s00277-020-04328-4

Schönrich G, Raftery MJ, 2019. The PD-1/PD-L1 axis and virus infections: a delicate balance. Front Cell Infect Microbiol, 9:207. https://doi.org/10.3389/fcimb.2019.00207

Sharafeldin N, Bates B, Song Q, et al., 2021. Outcomes of COVID-19 in patients with cancer: report from the National COVID Cohort Collaborative (N3C). J Clin Oncol, 39(20): 2232-2246. https://doi.org/10.1200/jco.21.01074

Shi Y, Wang G, Cai XP, et al., 2020. An overview of COVID-19. J Zhejiang Univ-Sci B (Biomed \& Biotechnol), 21(5):343-360. https://doi.org/10.1631/jzus.B2000083

Shumilov E, Hoffknecht P, Koch R, et al., 2021. Diagnostic, clinical and post-SARS-CoV-2 scenarios in cancer patients with SARS-CoV-2: retrospective analysis in three German cancer centers. Cancers (Basel), 13(12):2917. https://doi.org/10.3390/cancers 13122917

Tian JB, Yuan XL, Xiao J, et al., 2020. Clinical characteristics and risk factors associated with COVID-19 disease severity in patients with cancer in Wuhan, China: a multicentre, retrospective, cohort study. Lancet Oncol, 21(7):893-903. https://doi.org/10.1016/S1470-2045(20)30309-0
Wang BL, Huang Y, 2020. Immunotherapy or other anti-cancer treatments and risk of exacerbation and mortality in cancer patients with COVID-19: a systematic review and metaanalysis. OncoImmunology, 9(1):1824646. https://doi.org/10.1080/2162402X.2020.1824646

Wang LQ, Yin ETS, Wei GQ, et al., 2020. Weathering the storm: COVID-19 infection in patients with hematological malignancies. J Zhejiang Univ-Sci B (Biomed \& Biotechnol), 21(12):921-939. https://doi.org/10.1631/jzus.B2000423

World Health Organization, 2020. WHO Director-General's opening remarks at the media briefing on COVID-19-20 November 2020. https://www.who.int/director-general/speeches/ detail/who-director-general-s-opening-remarks-at-the-mediabriefing-on-covid-19---20-november-2020

Wu QJ, Chu Q, Zhang HY, et al., 2020. Clinical outcomes of coronavirus disease 2019 (COVID-19) in cancer patients with prior exposure to immune checkpoint inhibitors. Cancer Commun, 40(8):374-379. https://doi.org/10.1002/cac2.12077

Xu Z, Shi L, Wang YJ, et al., 2020. Pathological findings of COVID-19 associated with acute respiratory distress syndrome. Lancet Respir Med, 8(4):420-422. https://doi.org/10.1016/s2213-2600(20)30076-x

Yang Y, 2015. Cancer immunotherapy: harnessing the immune system to battle cancer. J Clin Invest, 125(9):3335-3337. https://doi.org/10.1172/jci83871

Yazaki S, Yoshida T, Kojima Y, et al., 2021. Difference in SARSCoV-2 antibody status between patients with cancer and health care workers during the COVID-19 pandemic in Japan. JAMA Oncol, 7(8):1141-1148. https://doi.org/10.1001/jamaoncol.2021.2159

Zhang HY, Wang LW, Chen YY, et al., 2020. Outcomes of novel coronavirus disease 2019 (COVID-19) infection in 107 patients with cancer from Wuhan, China. Cancer, 126(17):4023-4031. https://doi.org/10.1002/cncr.33042

Zhang L, Zhu F, Xie L, et al., 2020. Clinical characteristics of COVID-19-infected cancer patients: a retrospective case study in three hospitals within Wuhan, China. Ann Oncol, 31(7):894-901. https://doi.org/10.1016/j.annonc.2020.03.296

\section{Supplementary information}

Appendixes S1 and S2; Tables S1 and S2; Figs. S1 and S2 